\title{
Letters
}

\section{How political should a general medical journal be?}

\section{We cannot be apolitical}

EDITOR-Delamothe asks to what extent a general medical journal should be political. ${ }^{1}$ Every medical article published is the culmination of a long journey that started from a political decision: devoting resources to medical care and research. There is nothing to fear about being political, so long as we are prepared to accept the consequences and deal with the criticism of many who strongly believe that a person or a journal should be apolitical. The $B M / \mathrm{s}$ political stand is the clinical, scientific, social, political, and economic factors affecting health. ${ }^{2}$

What a reader expects from a journal such as the $B M J$ is that it maintains a balance in terms of the views expressed and scientific articles published. If there is controversy it has to be stated, and if there are conflicting views on the same topic they have to be given equal time and coverage. That is to be politically responsible, and, so far, the $B M J$ has been so.

What the journal cannot afford is to become politicised by allowing only one point of view to be expressed. Also, it cannot afford to politicise the argument and continuously publish long articles dealing with 11 September and its aftermath. The reason: 11 September is a consequence of a series of events transforming our world. To understand it, we have to analyse the unequal relation and misunderstanding between the West and Islam and vice versa; this implies dealing with historical, political, and cultural facts.

Is the $B M J$ or any other medical journal the right place to deal with 11 September and bridge this misunderstanding? I would certainly not pick the $B M J$ as my first source of information on the issue.

How much space should be devoted to politics? As much as it is necessary so long as you keep open to honest political debate and do not become politicised.

Guillermo A Herrera Taracena medical epidemiologist

Ozvantan Sokak 17/2, Teras Eveler, Yukari Ayranci, Ankara, Turkey

Competing interests: None declared.

Delamothe T. How political should a general medical journal be? BMJ 2002;325:1431-2. (21 December.)

2 About the BMJ. bmj.com/aboutsite/aboutbmj.shtml (accessed 3 Apr 2003).

\section{Medical journal is no place for politics}

EDITOR-The problem with medical journals entering into politics is that it subjects them to the accusation of bias. Delamothe's editorial reveals this in its reference to a "phoney war." That's a cheap shot, and not worthy of an editor of one of the most prestigious medical journals in the world.

You may disagree with your government's stance on Iraq, but that disagreement has no place in a medical journal. Cataloguing the health effects of weapons of mass destruction or debating (honestly and fairly) the merits and demerits of smallpox vaccine are appropriate for the pages of the journal.

It isn't appropriate, however, for you to use your influential position to trumpet your own political biases. Continuing to do so only discredits the journal. How will we know you haven't rejected papers simply because their findings disagree with your politics?

Pennie Marchetti family physician

Stow Primary Care, 4465 Darrow Road, Stow, OH 44224, USA

pmarchetti@ameritech.net

Competing interests: None declared.

1 Delamothe T. How political should a general medical journal be? BMJ 2002;325:1431-2. (21 December.)

\section{Medical journals may have had role in justifying war}

EDITOR-How political should a general medical journal be?' After my call earlier this year on the listserver of the World Association of Medical Editors for more debate in medical journals about the reasons for attacking Iraq, I received several messages from medical editors who believe that medical journals should not get involved in political issues. I think that medical journals in fact played an important part in providing the political justification for attacking Iraq.

I believe that most people in the United States and United Kingdom would have preferred not to launch a military attack on the people in Iraq. To persuade them to do so, they need to believe that they are being attacked. ${ }^{2}$ Medical journals have (unwittingly) had an important propaganda role in persuading the public that it is being attacked.

The table shows the growth in the number of articles on bioterrorism published in five major medical journals. To
Numbers of articles on bioterrorism and road traffic crashes published in five major medical journals: JAMA, New England Journal of Medicine, BMJ, Lancet, Annals of Internal Medicine

\begin{tabular}{ccc} 
Year & Bioterrorism & Traffic crashes \\
\hline 1999 & 2 & 18 \\
\hline 2000 & 6 & 26 \\
\hline 2001 & 44 & 22 \\
\hline 2002 & 72 & 56 \\
\hline
\end{tabular}

provide a yardstick against which to assess the comparative public health importance of bioterrorism, the table also includes the number of articles published on road traffic crashes. Articles were retrieved through a Medline search using the MeSH headings bioterrorism, and accidents, traffic. Road traffic crashes kill about 3000 people each day worldwide and disable about 30000 , and the global burden of disease from road traffic crashes is increasing. ${ }^{34}$

Of the 124 articles on bioterrorism, $63 \%$ originated in the United States and the rest in the United Kingdom. JAMA published the largest proportion of the articles $(47 \%)$, followed by the $B M J(21 \%)$, the Lancet $(16 \%)$, and the New England Journal of Medicine (15\%). The Annals of Internal Medicine published only two articles on bioterrorism. Importantly, in 2002 the BMJ published a theme issue on road traffic crashes, which accounts for much of the increase in articles on traffic crashes in 2002 . $^{5}$

Compared with a health problem that kills 3000 people per day, the public health importance of bioterrorism has been overemphasised in the leading medical journals. I am not implying that this is a deliberate attempt to alarm the population, but nevertheless it may have had this effect. As a result, medical journals may have unwittingly played an important political part in justifying war in Iraq.

Ian G Roberts professor of epidemiology and public health

London School of Hygiene and Tropical Medicine, London WC1E 7HT

ian.roberts@lshtm.ac.uk

Competing interests: None declared.

1 Delamothe T. How political should a general medical journal be? BMJ 2002:325:1431-2. (21 December.)

2 Chomksy N, Barsamian D. Propaganda and the public mind: comversations with Noam Chomsky. London: Pluto Press,

3 Murray CJL, Lopez AD. Global health statistics: a compendium of incidence, prevalence and mortality estimates for over 200 conditions. Harvard School of Publit Heath, Bo

4 Nantulya V, Reich M. The neglected epidemic: road traffic injuries in developing counties. BMJ 2002,324:1139-1141 5 Roberts I, Mohan D, Abbasi K. War on the roads. BMJ
2002;324:1107-8. 
Politics, health, and justice are intertwined EDITOR-I support Delamothe's editorial and the point made by several respondents that to try to ignore politics is itself deeply political because it allows other views to go unchallenged. ${ }^{12}$ Your pages should reflect a diversity of opinion. But perhaps the clearest bias of a journal concerned with health should be towards the poorest of society, not only because they usually have the lowest life expectancy but because they are also likely to have the weakest voice.

Health generally is embedded in social circumstances, and that relates not only to the division, but to the size, of the pie. However, public health has rarely been able to go beyond pointing to larger issues such as poverty, economic globalisation, and lack of political will. ${ }^{4}$

An ideological and political debate rages in the world, with enormous consequences to human health and wellbeing. These include the runaway epidemic of HIV/AIDS, famine in part caused by the loss of farming expertise as a whole generation of farmers sicken and die, and a persistent unwillingness by wealthy countries to keep their numerous promises for a fairer world, whether these relate to reducing hunger, funding the Global Fund to fight AIDS, tuberculosis, and malaria, or eliminating nuclear weapons.

There is an opportunity to narrow this ideological divide. The genie of technology and information is out of the bottle. Globalisation has drawn us so close together that the welfare of the developed world is no longer best assured by maintaining misery in the developing world. Convergence of these two ideologies may yet save us from a future riven by hatred, revenge, and the perennial fear of terrorism.

Colin D Butler postdoctoral fellow

National Centre for Epidemiology and Population Health, Australian National University, Canberra 0200, Australia

colin.butler@anu.edu.au

Competing interests: $\mathrm{CDB}$ is cofounder of an aid organisation (Benevolent Organisation for Development, Health and Insight (BODHI)).

1 Delamothe T. How political should a general medical journal be? BMJ 2002;325:1431-2. (21 December.)

2 Electronic responses. How political should a general medical journal be? bmj.com 2002. bmj.com/cgi/eletters/ 325/7378/1431 (accessed 3 Apr 2003).

3 Chambers R. Whose reality counts? Putting the first last. London: Intermediate Technology Development Group, London, 1997.

4 Mann JM. Leadership is a global issue. Lancet 1997;350:23 (suppl iii)

Butler CD. Inequality, global change and the sustainability of civilisation. Glob Change Hum Health 2000;1:156-72.

\section{Health is political}

EDITOR-With reference to Delamothe's editorial, of course a general medical journal should be more political. ${ }^{1}$ Health is political. It is so political that those who really want to have an impact on health shouldn't bother becoming doctors but should attempt to tackle the major causes of ill health, such as inequality and poverty.

Pandora Pound research fellow

Department of Social Medicine, University of

Bristol, Bristol BS8 2PR

pandorapound@blueyonder.co.uk
Competing interests: None declared.

1 Delamothe T. How political should a general medical journal be? BMJ 2002;325:1431-2. (21 December.)

\section{Politics could become evidence based with $B M /$ s help}

EDIToR-I agree with Delamothe that it is very difficult to separate politics and health, and I believe that it is perfectly legitimate for journals such as the $B M J$ to print articles that discuss political issues.

Since the $B M J$ has done such a good job of promoting evidence based medicine, perhaps the most important challenge for the $B M J$ in discussing the politics of health is to set an agenda of evidence based politics. It seems to me that politicians too often make policies on the basis of personal whims and dogma, rather than evidence. If the $B M J$ could shame politicians into introducing policies only if they can be justified by evidence it will truly have done a good job.

Adam Jacobs director

Dianthus Medical Limited, London SW19 3TZ ajacobs@dianthus.co.uk

Competing interests: None declared.

1 Delamothe T. How political should a general medical journal be? BMJ 2002;325:1431-2. (21 December.)

\section{Politics are part of general medical} journal

EDITOR-No politics in a general medical journal? ${ }^{1}$ This would be the thin edge of the wedge, and next thing you know there would be a ban on art, history, humour ...

Morris Doublet-Stewart principal general practitioner

Grasmere Street Health Centre, Leigh, Lancashire WN7 1XB

morris.doublet-stewart@gp-p92606.nhs.uk

Competing interests: None declared.

Delamothe T. How political should a general medical journal be? BMJ 2002;325:1431-2. (21 December.)

**In all, 366 people responded to the question posed on bmj.com: How much space should the $B M J$ devote to political issues? In comparison with current coverage, $45 \%$ wanted more or much more coverage, $31 \%$ the same, and $22 \%$ less or much less (bmj.com/misc/politics.shtml).Sharon Davies, letters editor

\section{Management of chronic obstructive pulmonary disease}

\section{Statement about theophyllines is} misleading

EDITOR-The editorial by Babu and Chauhan on the management of acute exacerbations of chronic obstructive pulmonary disease contains a serious error of fact. The Cochrane review by Barr et al is quoted to support their proposal that standard treatment for exacerbations of chronic obstructive pulmonary disease should include theophyllines. ${ }^{1}$ This review said no such thing.
The reviewers' conclusions were that there is no evidence to support the routine use of methyl-xanthines for exacerbations of chronic obstructive pulmonary disease. Methyl-xanthines do not appreciably improve forced expiratory volume in one second $\left(\mathrm{FEV}_{1}\right)$ during exacerbations, and cause adverse effects; evidence of their effect on admissions is limited. ${ }^{2}$

Although theophyllines were used by previous generations of doctors for managing acute exacerbations of asthma and chronic obstructive pulmonary disease, this use was not evidence based, and these agents have been shown to be associated with increased adverse effects (but no proved clinical benefit) for both groups of diseases. ${ }^{2}{ }^{3}$ I have occasionally had to deal with severe adverse effects (including cardiac arrest) when intravenous aminophylline had been given to patients with acute airflow obstruction by admitting medical teams, especially when strict safety precautions were not followed.

This misleading statement in a $B M J$ editorial could lead a new generation of doctors on call to restart the use of these toxic drugs, which are of unproved clinical benefit when given in addition to more modern treatment. This error of fact will require a prominent notice of correction in the journal.

B Ronan O'Driscoll consultant respiratory physician Hope Hospital, Salford M6 8HD

ronan.o'driscoll@srht.nhs.uk

Competing interests: None declared.

1 Babu KS, Chauhan AJ. Non-invasive ventilation in chronic obstructive pulmonary disease. BMJ 2003;326:177-8. (25 January.)

2 Barr RG, Rowe BH, Camargo CA Jr. Methyl-xanthines for exacerbations of chronic obstructive disease. Cochrane Database Syst Rev 2001;(1):CD002168.

3 Parameswaran $\mathrm{K}$ Belda J Rowe $\mathrm{BH}$ Addition of 3 Parameswaran K, Belda J, Rowe BH. Addition of with 2000;(4):CD002742

\section{Authors' reply}

EDITOR-We agree that the objective evidence for the benefit of methyl-xanthines on lung function and clinical outcome is limited and the risk of adverse events is notable, particularly if treatment is not supervised or monitored effectively. We do not advocate the routine use of oral or intravenous methylxanthines in mild to moderate exacerbations of chronic obstructive pulmonary disease.

However, in certain clinical circumstances methyl-xanthines may be used in severe exacerbations. These include an incomplete response to bronchodilators in the absence of any major risk factors for theophylline toxicity (such as drug interactions) and any cardiac disease, and when the concentrations of the drugs and the response can be monitored.

Both current international and national guidelines on the management of chronic obstructive pulmonary disease still recommend the use of theophylline in some severe exacerbations. The British Thoracic Society guidelines on managing chronic obstructive pulmonary disease say that intravenous 
methyl-xanthines by continuous infusion should be considered if the patient is not responding. ${ }^{1}$ Similarly, the international guidelines of the Global Initiative for Chronic Obstructive Lung Disease say that addition of an oral or intravenous methylxanthine can be considered in more severe exacerbations, ${ }^{2}$ as do those of the Centers for Evidence Based Medicine (www.nelh. co.uk/eboc). All these sources confirm the lack of benefit in lung function but do imply an improvement in self reported symptoms weeks after the exacerbation of chronic obstructive pulmonary disease.

We regret any confusion that the term "standard" treatment may have causedperhaps "available treatment for severe exacerbations" is more appropriate. We wanted to show the magnitude of the risk reductions of non-invasive ventilation in the context of other treatments used for severe exacerbations of chronic obstructive pulmonary disease. We do not agree that a new generation of doctors on call are likely to recommence the widespread use of methylxanthines on the basis of our article, certainly not when their use is already supported by national and international guidelines on managing severe exacerbations of chronic obstructive pulmonary disease. We therefore do not agree that it is a seriously misleading statement.

K S Babu research fellow

Southampton General Hospital, Southampton SO16 6YD

A J Chauhan consultant physician

St Mary's Hospital, Portsmouth PO3 6AD

Competing interests: None declared.

1 BTS guidelines for the management of chronic obstructive pulmonary disease. The COPD Guidelines Group of the Standards of Care Committee of the BTS. Thorax 1997;52(suppl 5):S1-28.

2 Pauwels RA, Buist AS, Calverley PM, Jenkins CR, Hurd SS Global strategy for the diagnosis, management, and prevention of chronic obstructive pulmonary disease. NHLBI/WHO Global Initiative for Chronic Obstructive Lung Disease (GOLD) Workshop summary. Am J Respir Crit Care Med 2001;163:1256-76.

\section{Parametric survival models may be more accurate than Kaplan-Meier estimates}

EDITOR-Lundin et al use Kaplan-Meier estimates of survival probabilities in their system for survival estimation in breast cancer (Finprog study, http://finprog. primed.info). ${ }^{1}$ They claim that researchers can obtain survival estimates based on actual data, rather than inferential estimates generated by a regression formula. However, any regression formula is based on actual data. More importantly, survival estimates from a regression model may be substantially more precise than Kaplan-Meier estimates when there are few patients in particular strata.

We have modelled prognosis of HIV positive patients starting treatment by using data from the Antiretroviral Cohort Collaboration (www.art-cohort-collaboration. org). ${ }^{2}$ Patients are allocated to 80 strata by using five prognostic factors: $\mathrm{CD} 4$ cell count, viral load, AIDS at start of treatment, age, and transmission group. In some strata few events were noted, and no deaths at all, so that estimation of survival probabilities by using Kaplan-Meier curves is impossible. In regression modelling, estimates for strata with few or no events borrow strength from the pattern of events across all categories of the prognostic variables.

In each graph in our figure survival estimates from the parametric model are contrasted with those calculated by using the Kaplan-Meier method. The two curves agree quite closely in (a) and (b), but the confidence interval for the parametric model is narrower. In (c) the estimates do not agree; moreover, the Kaplan-Meier curve peters out by two years due to lack of follow up, and the confidence interval is too broad to be a useful predictor of survival at one year, ranging from 5-95\%. Figure (d) shows a similar sized group to (c) but by chance there were no events in (d) despite having a worse risk profile (lower CD4), giving a completely misleading prediction of $100 \%$ survival.

The Kaplan-Meier estimates are less precise than parametric survival model estimates and may also be very inaccurate.

Margaret May statistician

Jonathan Sterne reader in medical statistics and epidemiology

Department of Social Medicine, University of Bristol, Bristol BS6 2PR

Matthias Egger professor of epidemiology

Department of Social and Preventive Medicine, University of Bern, Switzerland

Competing interests: None declared.

1 Lundin J, Lundin M, Isola J, Joensuu H. A web-based system for individualised survival estimation in breast cancer 1. BMJ 2003;326:29. (4 January.)

2 Egger M, May M, Chêne G, Phillips AN, Ledergerber B, Dabis F, et al. Prognosis of HIV-1-infected patients starting highly active antiretroviral therapy: a collaborative analysis of prospective studies. Lancet 2002; 360:119-129.
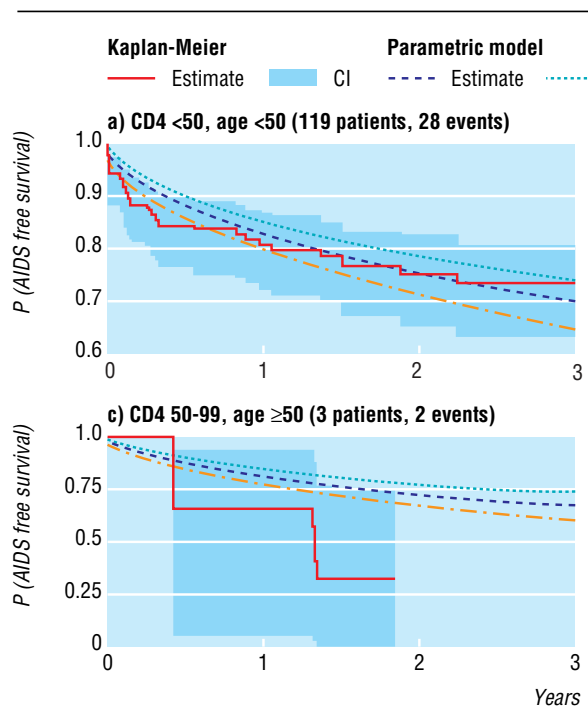

\section{Opiate withdrawal and botulism: stigma delayed treatment}

EDIToR-Merrison et al reported a difficult diagnostic case of wound botulism, which led to the formulation of a helpful diagnostic table for distinguishing clinical features from Guillain-Barré syndrome, MillerFisher variant, and myasthenia gravis. ${ }^{1}$ I report a case of wound botulism in a long term heroin user showing that a history of substance misuse can cloud the picture even more than the clinical presentation.

A man with a 20 year history of using street heroin had poor intravenous access and therefore injected blindly into his buttocks. After developing an abscess on one side he injected on the other for three weeks, then returned to the initial injection site, believing that it had healed.

$\mathrm{He}$ attended his local accident and emergency department after three days with malaise, dizziness, facial weakness, slurred speech, and difficulty swallowing. After triage he was judged to have a chest infection, with the implication that he was under the influence of substances, and he was asked to leave the department.

The next day he was reviewed at a community drug clinic with a presentation of muscle weakness, ataxia, ptosis, sluggish papillary responses, dysphagia, and dysarthria (normal transcribed language). $\mathrm{He}$ also had opiate withdrawal symptoms of piloerection, muscle pain, sweating without pyrexia, and tachycardia. Within a few hours of presentation to accident and emergency he had respiratory failure and was transferred to an intensive care unit. GuillainBarré syndrome and botulism were differentially diagnosed, and he was treated with botulinum antitoxin (before the toxin was isolated) and wound management.

Botulinum antitoxin was prescribed effectively after untangling the clinical pres-
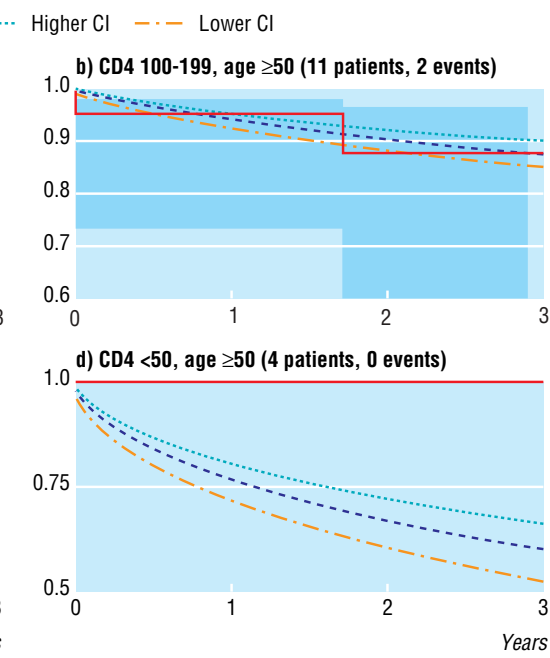

Survival curves predicted from parametric model with corresponding Kaplan-Meier estimates (with $95 \%$ confidence intervals) for different groups of patients who were injecting drug users, had AIDS at start of treatment, and had log viral load $>5$ 
entations, and he was out of hospital and back to normal within four weeks. This is in contrast to the treatment reported by Merrison et al, which did not include antitoxin treatment and resulted in neurological morbidity seven months after treatment.

The problems of management in both cases are associated with comorbid opiate withdrawal signs and symptoms and nonobvious cutaneous evidence of a wound infection, but the most important in the above reported case was the stigma of a history of injecting substance misuse.

Karl Marlowe specialist registrar

South London and Maudsley NHS Trust, London SW9 9HG

karlmarlowe@doctors.org.uk

Competing interests: None declared.

Merrison AFA, Chidley KE, Dunnett K, Sieradzan KA Wound botulism associated with subcutaneous drug use BMJ 2002;325:1020-1. (2 November.)

\section{Shapely centrefolds}

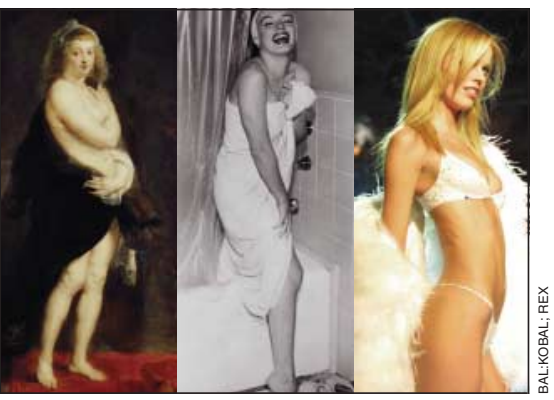

Are women changing or is Playboy?

EDITOR-First, sexual images were blamed for causing sex crime. Now, it seems they're responsible for eating disorders too. Voracek and Fisher's analysis of the changing shape of Playboy centrefolds tells us more about the changing face of sexual material than the changing shape of women's bodies. ${ }^{1}$ The authors are correct to challenge existing research that claims that women in sexual materials represent the "hourglass" figure, but despite a more thorough analysis of Playboy, it is fair to point out that Playboy is only one sex publication and is well known for having close links with fashion and mainstream media.

Had the authors chosen to analyse other magazines, they may well have seen an increase in women's shape, body size, or even age of models. ${ }^{2}$ Furthermore, they overlook other reasons why images of women in Playboy have changed. Anecdotal evidence shows that more women are looking at sexually explicit materials, particularly those seen as easily accessible and similar to "fashion magazines"; and evidence shows that they are more critical of female bodies than men are. ${ }^{3}$ Therefore rather than Playboy representing a changing shape of women, it may be that women's distorted views on body image are now being played out through pages of sexual magazines catering for an increase in female readership.

Whatever the explanation, it is important to remember two issues when analysing sexual materials. Firstly, the range of titles and topics covered is vast, catering for every taste. Secondly, it is overly simplistic to say that media images alone cause women's body image to change. ${ }^{2}$ Several complex social factors lead to eating disorders, not a picture in Playboy.

Petra M Boynton lecturer

Department of Primary Care and Population Sciences, University College London, London WC1E 6BT

p.boynton@pcps.ucl.ac.uk

Competing interests: None declared.

1 Voracek M, Fisher ML. Shapely centrefolds? Tempora change in body measures: trend analysis. $B M$ 2002;325:1447-8. (21 December.)

2 Boynton PM. The contextual evaluation of research on sexually explicit materials. Birmingham: Aston Busines School, Aston University. [PhD thesis.]

3 Boynton PM. Is that supposed to be sexy? Women discus women in "top shelf" magazines. J Community Applied So Psychol 1999;9.

\section{Sexual desire, fatness, and class are} connected in sociohistorical context

EDITOR-Voracek and Fisher analysed the changing shape of centrefold models in Playboy and found that they seemed to be becoming thinner. ${ }^{1}$ In fact, the principal eating disorder in the United Kingdom today is overeating. Its consequence, obesity, is vastly more important as a public health issue than anorexia nervosa. Obesity is also a progressive condition, unlike anorexia nervosa, which tends to ameliorate with age.

I speculate that in society the changes in the "maximally sexually attractive" woman's body, from the chubby Mrs Rubens to the sinewy model Eva Herzigova, are due to the social significance of fatness. In the 17 th century being thin indicated poverty-the poor laboured hard, starved, and as a result of overcrowding and poor sanitation contracted infectious diseases. Being fat represented ease - the rich did less physical work, ate plenty, and lived in more sanitary conditions. In the 21st century, in this part of the world, this has reversed. Being fat implies a bad, cheap, energy rich diet and a lack of physical activity and is associated with being poor. Being thin is, however, associated with wealth, presumably through greater health awareness, a healthier diet, and more opportunity for recreational exercise.

With this theory you don't have to assume a genetically inbuilt attraction to a given body mass index, ratio of hip to waist measurement, or fertility. One only needs to assume (or observe) that people are attracted by social dominance (high social class). Social dominance is associated with health and longevity. In the 17th century the rich lived longer than the poor partly because they were better nourished. Nowadays rich people live longer because poor people are unhealthily fat and die earlier, from the so called diseases of affluence.

Of course there is geographical as well as historical variation, and I assume that in a country where starvation is significant the maximally sexually attractive body is fatter. The person with anorexia nervosa is, however, a different matter. By definition this is an abnormal case, and you should look for the individual causes, not the societal ones.

Daniel McQueen staff grade psychiatrist St Bernard's Hospital, Southall UB1 3EU daniel.mcqueen@virgin.net

Competing interests: None declared.

1 Voracek M, Fisher ML. Shapely centrefolds? Tempora change in body measures: trend analysis. BMJ 2002;325:1447-8. (21 December.)

\section{A curriculum can be latent and informal}

EDITOR-Prideaux has provided an interesting and useful summary of approaches to a medical school curriculum. ${ }^{1}$ However, there are two parallel curricular processes at work.

The first is the latent curriculum, first described by Eisenberg, whereby students learn what is "really" important from role models, especially clinicians. For example, students continue to report that some specialists denigrate family medicine as a career path because it is not intellectually challenging or "interesting." Another longstanding example is the dismissal of behavioural and social science as "soft" and less worthy of attention than the biological sciences.

The second is the informal curriculum. I differ from Howarth in that I take this to be the curriculum that students themselves create outside of the formal curriculum. One example is the prevalence of workshops on the business of medicine, generally organised by the students out of hours. Another more altruistic example is the development of sessions on social issues, including reproductive choice.

We must learn from and respond to what students see as lacks in the formal curriculum as well as to the attitudes expressed by influential role models that shape students' behaviour.

Carol P Herbert professor of family medicine Faculty of Medicine and Dentistry, London, ON, Canada N6A 5C1

carol.herbert@fmd.uwo.ca

Competing interests: None declared.

1. Prideaux D. $\mathrm{ABC}$ of learning and teaching in medicine curriculum design. BMJ 2003;326:268-70. (1 February.)

\section{Dataset on deaths related to taking ecstasy looks incomplete}

EDITOR-I wonder whether the data of Schifano et al, on deaths related to taking ecstasy in England and Wales, are complete During their study (1 August 1997 to 31 July 2000), 45 coroners' cases in which the toxicological findings indicated that one of the "ecstasy" group of drugs was implicated in the cause of death were investigated in my laboratory. It is unlikely that we received more than half of the samples related to ecstasy deaths in England and Wales. This implies that the way in which coroners, or their pathologists, incorporate toxicological findings in their causes of death is not uniform. Future studies could use not only the 
coroners' reports but also the original toxicology and pathology reports.

Our data contain some additional information that complements those of Schifano et al. Twenty seven $(60 \%)$ of our cases had notable concentrations of ethanol in either blood or urine. In many cases the urine alcohol concentration was higher than the blood concentration, presumably reflecting the prolonged agonal process often associated with fatal ecstasy misuse. In the investigation of any drug misuse death blood, urine, and stomach contents should be analysed whenever they are available.

In none of our cases was methylenedioxyamphetamine (MDA) alone detected. Tablets containing only MDA are uncommon. Thus some of the deaths reported by coroners as being due to MDA alone may reflect the mistranscription of the toxicological data placed in evidence at the inquest.

Morphine was detected in $16(36 \%)$ of our cases. Most of these probably reflect concomitant heroin use. Methadone was found in only four cases (9\%). Benzodiazepines, (either diazepam or temazepam or both) were found in eight cases (18\%). Other prescription only medicines found in less than $10 \%$ of our cases included selective serotonin reuptake inhibitors, tricyclic antidepressants, and phenothiazines.

A R W Forrest professor of toxicology

University of Sheffield, Medico-legal Centre,

Sheffield S3 7ER

r.forrest@sheffield.ac.uk

Competing interests: None declared.

1 Schifano F, Oyefeso A, Webb L, Pollard M, Corkery J, Ghodse AH. Review of deaths related to taking ecstasy,
England and Wales, 1997-2000. BMJ 2003;326:80-1. (11 January.)

\section{Prisons, too, are institutions for psychiatric care}

EDITOR-In their editorial on the reinstitutionalisaton of mental health care Priebe and Turner overlook an important current place of institutional psychiatric care-the prison service. ${ }^{1}$ Like the expansion of forensic psychiatric services, this has been a global phenomenon, reported in the United Kingdom, the United States, and Europe.

In UK prisoner populations $4-10 \%$ of prisoners on remand and 2-7 $\%$ of sentenced prisoners have psychotic illnesses. ${ }^{2}$ Numbers become much higher if those with personality disorders and substance misuse are included. Figures such as these prompted one American psychiatrist to call prisons the last mental hospitals left open after the closure of the asylums. ${ }^{3}$

The reasons for this development are complex; a review from Germany of the role of prisons as new asylums identified diverse factors causing this unfortunate development. ${ }^{4}$ They included changes in the provision of psychiatric care and the reluctance of general psychiatric services to accept offenders with mental disorders because of a lack of secure accommodation, beds, and staff with appropriate skills and experience.
A large amount of still unmet need has partly driven the expansion of forensic psychiatric services. Rather than "sucking" resources away from those most in need of psychiatric care, forensic services could be seen as failing to keep pace with the mental health needs of an expanding prison population. The appropriate manner to deliver mental health services to this neglected and needy group is an important question for the whole of psychiatry. In the meantime an old institution seems to be taking on a new role.

Jay E Smith consultant in forensic rehabilitation John Howard Centre, London E9 2AT jay.smith@ukgateway.net

Competing interests: None declared.

1 Priebe S, Turner T. Reinstitutionalisation in mental health care. BMJ 2003;326:175-6. (25 January.)

2 Gunn J. Future directions for treatment in forensic psychiatry. J Forensic Psychiatry 2000;176:332-8.

3 Gilligan J. The last mental hospital. Psychiatr O 2001;72: 45-61.

Konrad N. Prisons as new asylums. Curr Opin Psychiatry 2002;15:583-7.

\section{Faxing helps deaf people access health services in Spain}

EDIToR-Jones and Gill described the communication problems experienced by ethnic minority groups in their attempts to gain access to NHS healthcare services. Several readers subsequently reported that deaf people encountered comparable obstacles and that rapid connection to an interpreting service was no solution..$^{23}$ Evidently, users with hearing deficiencies face enormous barriers to communicating with any health agency that offers services through telephone contact.

In Spain access to in situ emergency health care is provided by a fast dia telephone call (061 or 112). As the public company responsible for the 061 service in Andalusia, we designed a new system for deaf people to access emergency services. Taking advantage of the widespread use of fax machines by deaf people (over $70 \%$ of the deaf population in Andalusia possess a fax machine), we developed and validated a medical questionnaire for users to keep at home. In an emergency the questionnaire is completed and faxed to the 061 centre. Questions for yes/no responses are supported by drawings, and diagrams are included, to be marked as necessary. The questionnaire contains adequate data for an emergency coordinator to evaluate the nature of the emergency, the type of disease involved, the severity of the situation, and other relevant data.

On the basis of this fax alone, the coordinator can assign the most appropriate transport (fully equipped mobile intensive care unit, ambulance with medical or non-medical care) or referral to family doctor, police, or fire brigade, etc. Simultaneously, the coordinator faxes the user a selection of specially designed medical advice pages that illustrate the measures to be taken until help arrives. ${ }^{4}$

This graphic based method could also be readily adapted to serve people in emergency situations who are not fluent in the language of the country they find themselves in. The need for a feasible solution has become even more pressing, especially given the escalating mobility within and into Europe.

Manuel J Castillo-Garzon professor of medical physiology mcgarzon@ugr.es

Francisco J Gomez associate professor of medicine School of Medicine, University of Granada, E-18071 Granada, Spain

J Alberto Raya emergency care physician

Carmen Martin emergency care physician

061 Health Emergency Service, EPES, 18014

Granada

Competing interests: None declared.

1 Jones D, Gill P. Breaking down language barriers. BMJ 1998;316:1476.

2 Irwin J, Martin S. Don't forget deaf people. $B M J$ 1998;317:817.

Carter J, Hare-Cockburn K. Sign here, please. BMJ 1998;317:817

4 Raya JA, Martin C, Gomez FJ, Castillo M. Acceso telefónico para sordos al Sistema de Emergencias Sanitarias 061 Medicina Clínica (Barc) (in press).

\section{Peer review should not be anonymous}

EDITOR-With reference to the news item by White, ${ }^{1}$ peer review may be necessary, but it is open to bias and abuse, especially when referees are anonymous. To shelter under a cloak of anonymity is cowardly, and it is surprising that the editors of many eminent journals still permit this practice. Anonymous letters should be ignored and placed in the wastepaper basket where they belong.

Honest authors should not resent constructive criticism. Indeed they should welcome it as they will often learn much to their advantage. Discussion is the breath of life to research, but the manner in which anonymous "experts" sometimes express their opinions could permanently discourage young researchers with real potential, especially as vicious and hurtful comments have to be endured without the opportunity to obtain an explanation. Furthermore, it is not unknown for original ideas to be purloined while turning down a paper.

The carping critics of the arts, theatre, and literature have the honesty and dignity to sign their articles in the press and periodicals to which they contribute. Why should medicine, the greatest art of them all, appear to be so fearful of reprisal?

Harry Morrow Brown consultant allergist Highfield House, Highfield Gardens, Derby DE22 1HT

harry@morrow-brown.freeserve.co.uk

Competing interests: None declared.

1 White C. Little evidence for effectiveness of scientific peer review. BMJ 2003;326:241. (1 February.)

\section{bmj.com}

Letters appearing here are an edited selection of rapid responses originally posted on bmj.com

We ask for all letters to the editor to be submitted as rapid responses via bmj.com

For advice see: bmi.com/rapidresponses 